\title{
Prosthetic rehabilitation using an obturator in a fully edentulous patient who had partial maxillectomy
}

\author{
Yoo-Jin Chung,', Jong-Jin Kim¹, Jin Baik', Hyun-Suk Cha², Joo-Hee Lee ${ }^{2 *}$ \\ 'Divison of Prosthodontics, Department of Dentistry, Asan Medical Center, Seoul, Republic of Korea \\ 'Divison of Prosthodontics, Department of Dentistry, Asan Medical Center, College of Medicine, University of Ulsan, Seoul, \\ Republic of Korea
}

Prosthetic rehabilitation of an edentulous patient who has a maxillary defect is difficult to achieve for many clinicians. The maxillary defect causes leakage of air during pronunciation and compromises denture stability, support and retention by reducing denture-bearing area and breaking peripheral seal. In these patients, the sizes and shapes of defects are very important factors which attribute to prognosis of maxillary obturators. This case report shows the prosthetic rehabilitation of the patient who had maxillectomy on the right maxillary sinus because of squamous cell carcinoma. The patient had a stepwise treatment protocol which started with pre-operative dental examination and followed by surgical, interim and definitive obturation phase. In this case, an acceptable level of retention could be obtained due to well-defined static defects and the preserved premaxillae and the patient was satisfied with the result of the treatment in the aspect of function and esthetics. (J Dent Rehabil Appl Sci 2018;34(4):331-7)

Key words: oral cancer; maxillectomy; obturator; complete edentulous

\section{서론}

구강과 인두에 발생하는 양성 및 악성 종양은 가장 흔 하게 발생하는 종양 중 하나이다. 외과적 수술과 더불어 방사선 치료, 약물 치료가 이러한 구강암에 대한 가장 보 편적인 치료법이라고 할 수 있는데, 만약 외과적 제거 방 법을 적용하게 되면 환자는 상악골에 결손부를 갖게 된 다. ${ }^{1}$ 상악골 결손 환자들을 보철적으로 재건하고자 하는 여러 증례들이 보고되고 있으나, 그 중 무치악 환자들의 치료에 관한 보고들은 적다. Beumer는 그의 저서에서 상 악골 결손을 갖는 무치악 환자의 보철적 수복 과정을 기 술하였는데, 상악골 절제술을 시행하기에 앞서 환자 정

*Correspondence to: Joo-Hee Lee

Professor, Division of Prosthodontics, Department of Dentistry, Asan Medical Center, College of Medicine, University of Ulsan, 88 Olympic-ro 43-gil, Songpa-gu, Seoul, 05505 , Republic of Korea

Tel: +82-2-3010-3850, Fax: +82-2-3010-6967, E-mail: ljh111911@hanmail.net

Received: August 6, 2018/Last Revision: August 20, 2018/Accepted: August 23, 2018
\end{abstract}

보의 획득, 환자 상담, 그리고 향후 보철치료 계획 수립의 중요성을 강조하였다. 그리고 수술 직후 거즈 유지 및 환 부 보호를 위한 수술후 폐쇄 단계, 환부의 치유과정 동안 저작을 돕고 심미성을 개선해 주는 이행 폐쇄 단계를 거 쳐 최종 폐쇄 단계에 이르는 체계적인 치료 프로토콜을 소개하였다. ${ }^{2}$

본 증례는 편평상피암에 이환된 우측 상악동 부위에 상악골 절제술을 받은 무치악 환자로 술전 치과 검진, 수 술용 폐쇄장치, 이행 폐쇄장치, 그리고 최종 폐쇄장치에 이르는 단계적 치료 과정을 통해 수술 후 4개월 뒤 보철 적 재건을 완료하였다. 이후 1 년 간의 경과 관찰을 통해 양호한 예후를 얻었기에 이를 소개하고자 한다. 


\section{증례보고}

본 증례의 환자는 65 세의 남자 환자로서 우측 상악동 부위로부터 우측 안와까지 이르는 편평상피암을 진단받 았다. $\mathrm{T} 3 \mathrm{~N} 0 \mathrm{M} 0$ 로 평가 되었고 상악골 부분 절제술 계획 되어 술전 치과 검진을 위해 내원하였다.

\section{1. 술전 보철 계획 단계}

초진 시 상악은 무치악 상태로 ovoid한 악궁 형태를 보 이고 있었으며 하악은 우측 제 2 대구치의 결손과 좌측 구 치부의 치경부 마모증 및 경도의 전치부 총생 관찰되었 다. 상악에 종양으로 인한 돌출성의 구개부 병변은 관찰 되지 않았으며 환자 문진 결과 기존의 총의치를 불편 없 이 사용하고 있었다(Fig. 1). 환자는 복부 대동맥류가 있 어 혈관 확장제를 복용하고 있어 혈관외과와의 협진 하 에 수술 계획이 수립되었다. 편평상피암의 재발 가능성을 고려하여 외과적 재건이 아닌 보철적 재건을 선택하였고 ${ }^{3}$ 상하악 알지네이트 인상을 채득하여 진단 모형을 제작해 이비인후과로부터 수술 범위를 확인하였다(Fig. 2A). 술 전 악간 관계를 기록해 두기 위해 기록상과 교합제를 제
작하여 중심위로 교합 채득하였다(Fig. 2B). 채득한 교합 기록에 따라 진단 모형을 반조절성 교합기에 마운팅하였 다. 수술 전 치과 내원 시 환자와 향후 보철적 재건 계획 에 대해 충분의 논의하였고 폐쇄 장치를 이용한 상악 결 손부 폐쇄의 결과와 한계점 등에 대해 고지하였다.

\section{2. 수술후 폐쇄 단계}

수술용 폐쇄 장치를 제작하기 위해 마운팅 된 상악 무 치악 모형을 계획된 절제 범위에 맞추어 변형시켰다. 절 제가 예상되는 우측 상악 치조제의 협측 사면을 삭제하 여 수술용 폐쇄 장치의 변연이 내측으로 들어오게 함으 로써 수술 부위의 조직이 자극 되는 것을 방지하고 환자 의 불편감을 감소시킬 수 있었다. Beumer는 무치악 환자 에서 수술용 폐쇄장치를 기록상과 같은 형태로 제작하는 것을 제안하였지만 ${ }^{2}$ 본 증례에서는 교합제를 추가한 형 태로 제작하여 연하 시 교합제와 대합치의 접촉을 통해 폐쇄장치의 유지를 꾀하고자 하였다(Fig. 3A, 3B). 이 때 전치부를 포함하여 최대한 여러 치아에서 접촉을 이루도 록 교합제를 형성하되 절제가 예상되는 범위의 상악 구 치부에서는 접촉하지 않도록 조절하였다. 교합제를 투명
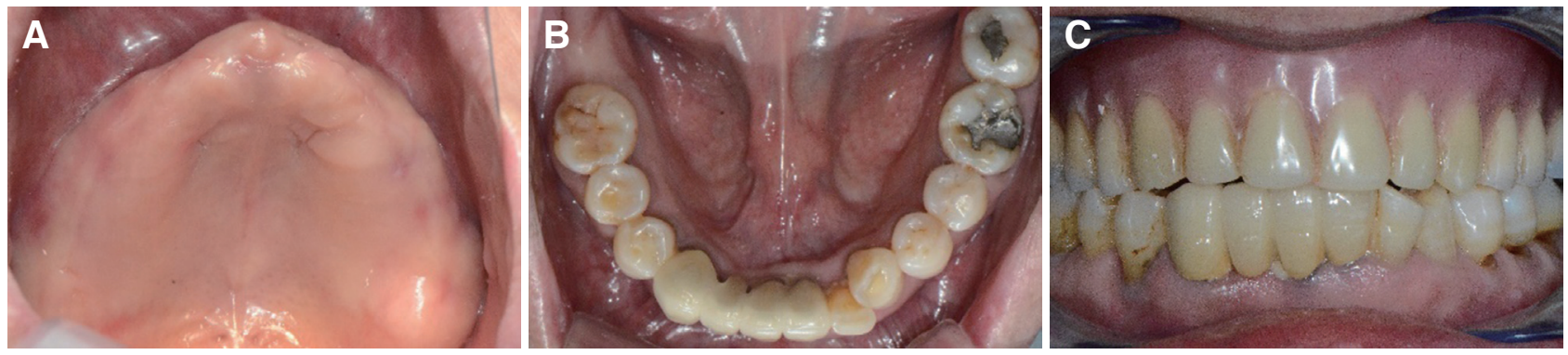

Fig. 1. Preoperative intraoral photographs. (A) Maxillary occlusal view, (B) Mandibular occlusal view, (C) Frontal view with old prostheses.
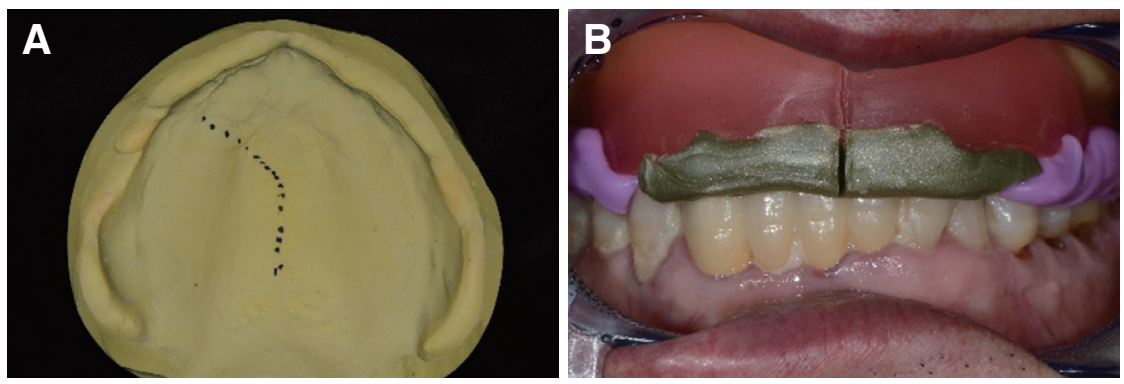

Fig. 2. Presurgical prosthetic planning. (A) Surgical margin on the study cast, (B) Centric relation record registration. 
레진(Ortho-Jet, Lang Dental Mfg Co., Wheeling, USA) 으로 온성하였고 수술 직후 환자에게 수술용 폐쇄 장치 를 장착하였다(Fig. 3C).

수술 2주 후 결손부에 넣어두었던 거즈는 제거하였고 (Fig. 3D) 환자는 유동식을 섭취하는 중이었으나 적절 한 유지가 얻어지지 않아 비강 누출이 발생하였다. 이에 적합도 증진을 위해 자가 중합형 레진(ProBase, ivoclar vivadent $\mathrm{AG}, \mathrm{Schaan}$, Liechtenstein)과 조직 이장재 (SOFT-LINER, GC, Tokyo, Japan)로 상악골 결손부위 의 의치상을 이장하였다(Fig. $3 \mathrm{E})$. 하지만 결손부 변연의 치유가 완전하지 않아 결손부의 언더컷을 이용한 유지 증진은 얻기 어려웠고 연하 시 대합치와의 접촉을 통해 폐쇄장치의 안정을 얻도록 교합조정 시행하였다.

\section{3. 이행 폐쇄 단계}

수술 4주 후부터 방사선 치료 진행하였고 수술 12 주 후 방사선 치료 완료된 상태로 치과에 내원하였다. 결손 부 변연의 연조직 치유가 진행되어 보다 명확한 경계를 보였으나 방사선 치료로 인한 점막염과 치은의 발적이 관찰되었다(Fig. 4A). 이행 폐쇄 단계를 위해 수술용 폐 쇄장치를 변형하기로 결정하였고 수술 전 채득했던 중 심위 기록이 기존의 수술용 폐쇄장치에 반영되어 있으 므로 단순히 치아 배열을 추가함으로써 이행 폐쇄장치 를 제작할 수 있었다. 이전에 이장했던 조직 이장재를 제 거하고 변화한 조직면에 맞추어 재이장 시행하였고 환자 의 심미적 요구를 충족시키기 위해 상악 6전치 인공치아
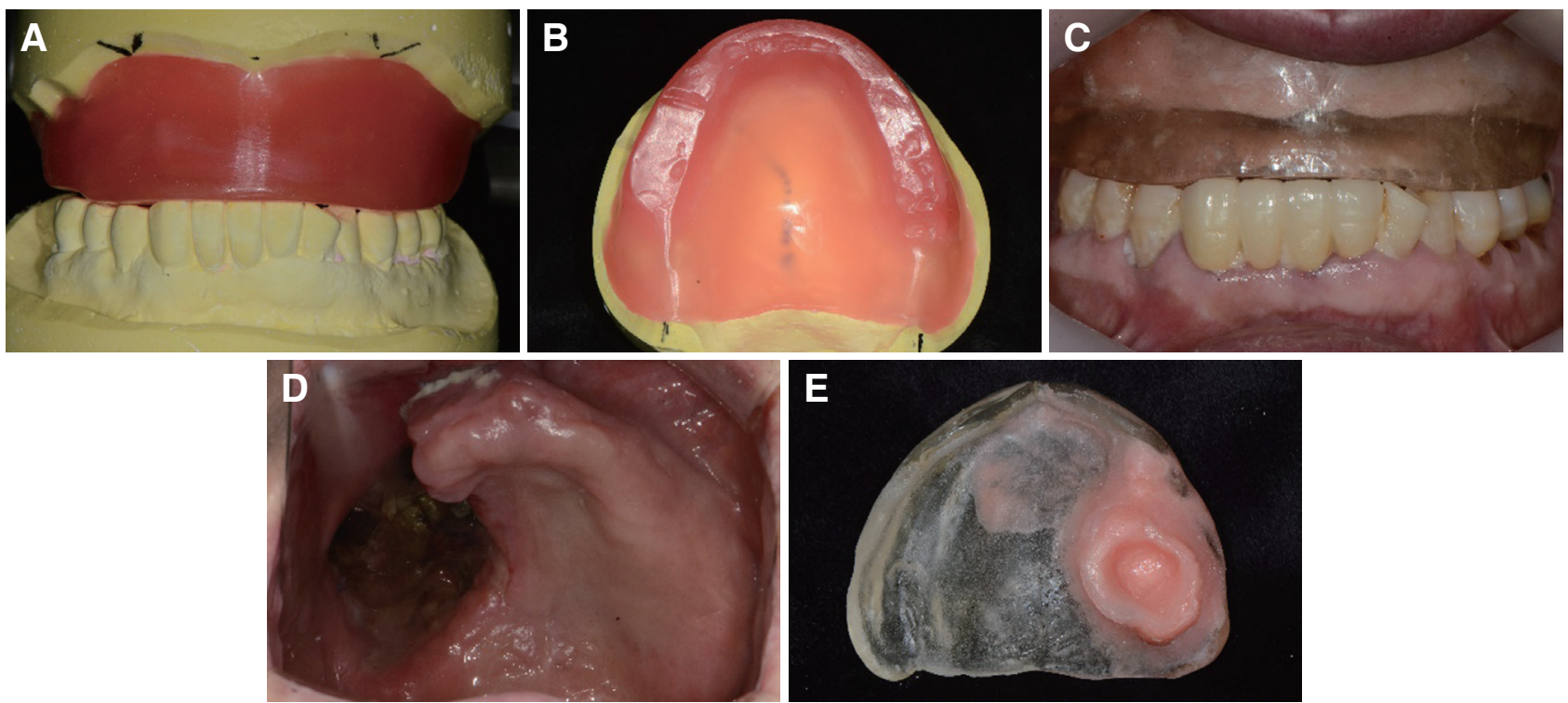

Fig. 3. Surgical obturation phase (A, B) Occlusal rim for surgical obturator, (C) Surgical obturator made of clear acrylic resin, (D) Maxillary occlusal view 2 weeks after maxillectomy, (E) Relined surgical obturator.
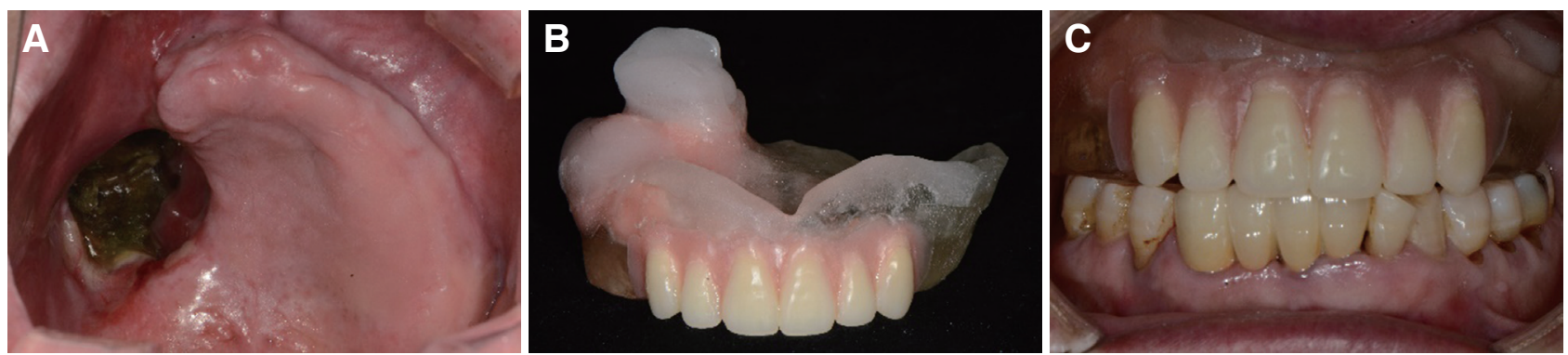

Fig. 4. Interim obturation phase. (A) Maxillary occlusal view 12 weeks after maxillectomy, (B) Modification of surgical obturator, (C) Intraoral photograph with modified surgical obturator. 
(Biotone, Dentsply International, York, USA)를 추가하 였다(Fig. 4B, 4C). 구치부는 교두가 있는 인공치아를 배 열할 경우 측방 간섭으로 인해 장치의 탈락이 심해질 수 있어 기존의 교합제 형태를 유지하였다.

\section{4. 최종 폐쇄 단계}

수술 4개월 후 방사선 검사 시행한 결과 편평상피암 병 변의 온전한 제거가 확인 되었고 그에 따라 주기적인 경 과관찰 단계로 이행되었다. 구강내의 결손부 또한 충분 한 치유가 이루어져 변연이 명확하고 깨끗하였다(Fig. $5 \mathrm{~A})$. 따라서 최종 폐쇄장치의 제작을 결정하였다.

최종 폐쇄장치의 제작을 위해 먼저 알지네이트 인상 재를 이용하여 예비인상을 채득하였다. 진단 모형을 제 작하고 자가중합형 아크릴릭 레진(SR Ivoren, Ivoclar Vivadent AG)으로 개인 트레이를 제작한 뒤 모델링 콤 파운드 왁스(Peri-compound, GC)를 이용해 통상적인 변연 형성 방식으로 트레이를 연장하였다. 이 때 수술하 지 않은 좌측 전정부와 상악골 결손부의 내측 변연을 먼 저 형성해 트레이가 안정적으로 안착될 수 있도록 하였 다. 그리고 결손부의 전방, 후방, 외측방의 변연 형성을 시행하였고 변연이 과연장 되어 조직이 지나치게 신장 되지 않도록 콤파운드 왁스의 점도를 주의 깊게 조절하 였다(Fig. 5B, 5C). 결손부의 변연 형성시 모델링 콤파운
드 왁스에 반흔대가 인기된 것을 관찰할 수 있었다(Fig. $5 \mathrm{D})$. 변연 형성이 끝난 뒤 실리콘 인상재(EXAMIXFINE, GC)로 정밀 인상 채득하였고 최종모형을 제작하 였다(Fig. 5E).

기록상과 교합제를 제작하여 구강 내에서 수직교합고 경을 결정한 뒤 중심위로 유도하여 악간 관계를 채득하 였다. 이 때 기록상의 안정성이 떨어지므로 의치 적합 시 험재(Fit checker II, GC)를 이용해 추가적인 유지를 얻었 으나 결손부의 기록상에 압력이 가해지면 탈락되므로 저 항성이 있는 왁스 대신 흐름성이 좋은 실리콘(Occlufast Rock, Zhermack, Rovigo, Italy)을 이용하였다. 안궁이전 시행한 뒤 반조절성 교합기에 마운팅하였고 인공치아를 배열하였다(Fig. 6A, 6B). 완성된 납의치를 구강 내에 시 적 하여 교합고경, 안모의 심미성, 교합 관계를 확인하였 고 더 높은 적합도를 얻기 위해 낮은 점조도의 실리콘 인 상재(Imprint II, 3M ESPE, St. Paul, USA)를 이용하여 폐구법으로 wash impression 채득하였다(Fig. 6C). 열중 합 레진을 이용해 통상적인 방법으로 폐쇄장치를 온성하 였고 상악골 결손부로의 연장 부위는 돔 형태로 제작하 여 비강의 분비물이나 음식물이 저류되지 않도록 하였다 (Fig. 7A). 최종 폐쇄 장치를 환자에게 장착해 주었고 주 기적인 재내원을 통해 압통점을 조정하였다. 환자는 적 정 수준의 유지력을 가진 폐쇄장치를 통해 무리 없이 식 사할 수 있었고 심미적으로도 만족하였다(Fig. 7B).
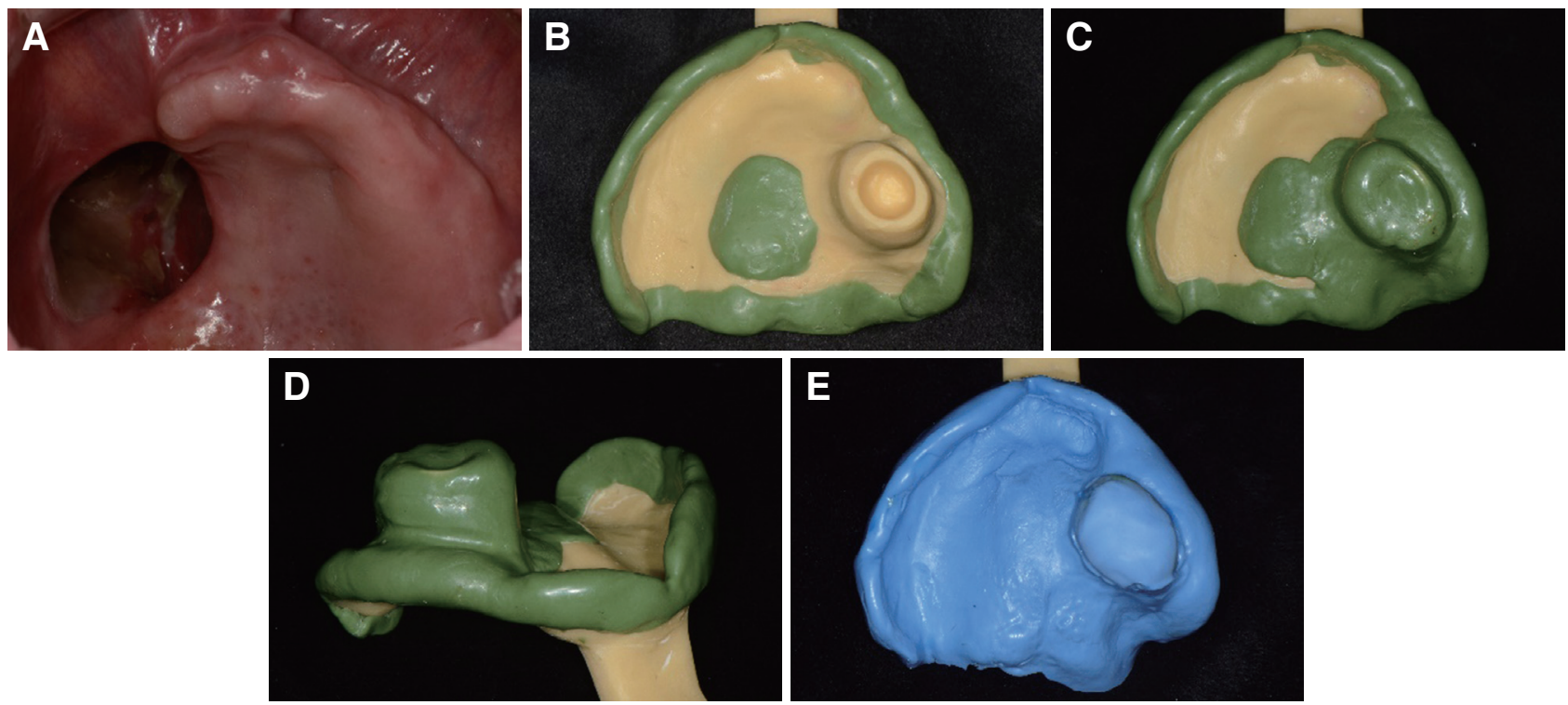

Fig. 5. Definitive obturation phase. (A) Maxillary occlusal view 16 weeks after maxillectomy, (B, C) Border molding of the definitive obturator, (D) Scar band presented on border molding compound wax, (E) Final impression completed with polyvinyl siloxane. 

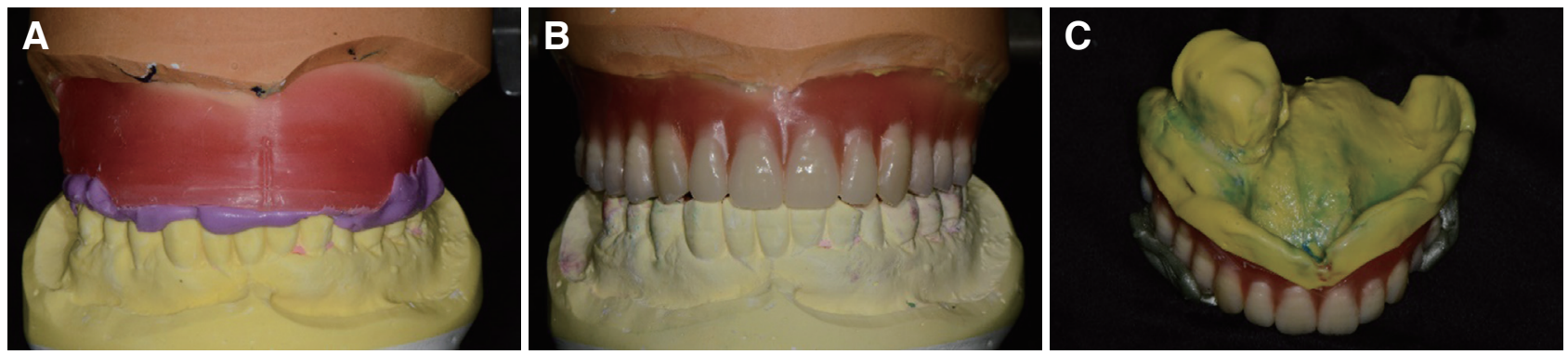

Fig. 6. (A) Mounting of the master cast, (B) Wax obturator, (C) Wash impression completed with light-body polyvinylsiloxane.
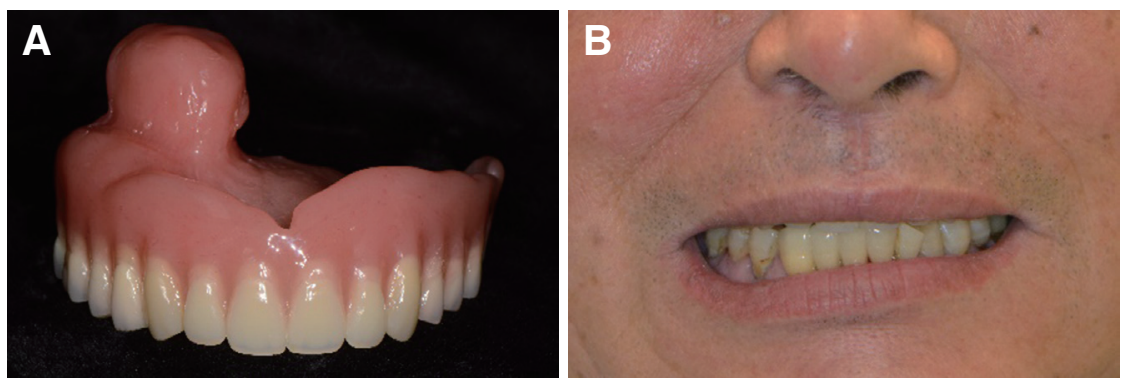

Fig. 7. (A) Definitive obturator, (B) Extraoral photograph after delivery of definitive obturator.

\section{5. 경과 관찰}

주기적인 재내원을 통해 내면 적합도를 확인하고 교합 조정을 시행하였다. 최종 장착일로부터 7개월이 지난 뒤 결손부 주변 조직의 수축으로 유지력이 다소 감소되어 결손부로의 연장 부위를 자가 중합형 레진(ProBase, ivoclar vivadent AG)으로 첨상하였다. 최종 장착일로부터 1 년 뒤 수술 부위에 편평상피암의 재발 소견은 발견 되지 않았으며 최종 폐쇄장치 역시 문제 없이 양호하게 기능 하였다.

\section{고찰}

상악골 절제술을 받은 무치악 환자는 의치의 지지, 유 지, 안정을 얻기 위한 해부학적 구조가 결손 되기 때문에 가철성 장치의 예후가 좋지 않다. 따라서 임플란트를 이 용해 지지와 유지를 보강한 폐쇄장치 치료를 고려해야 하지만 방사선 치료의 기왕력이 있거나 경제적인 이유로 임플란트 식립을 동반한 보철적 재건이 불가한 경우가 많이 있다. 따라서 무치악 환자의 잔존 상악골과 해부학 적 구조를 최대한 이용하여 폐쇄장치를 제작하는 노력이
필요하며 이를 위해 체계적이고 단계적인 치료 과정을 이 행해야 한다.

본 증례에서는 수술후 폐쇄 단계 시 교합제를 추가 한 형태의 폐쇄장치를 이용하였다. 얇은 기록상의 형태 로 폐쇄장치를 제작할 경우 구강 내에서 장치가 유지되 지 못하므로 환부를 보호하거나 드레싱 거즈를 유지하 는 기능을 하기 위해서는 별도의 처치가 필요하다. 관골 궁이나 전비극, 구개골 등에 스크류나 와이어를 이용해 폐쇄장치를 고정하는 방법이 있는데 이를 위해서는 수 술 중에 장치의 조절 및 고정이 시행돼야 한다. ${ }^{2}$ 수술 중 에 이러한 처치를 하지 못한 경우는 본 증례의 방법처럼 교합제의 형태로 폐쇄장치를 제작해 환자가 장치를 물고 있게 함으로써 장치를 유지시킬 수 있다. 이 때 결손부의 교합제 부위는 대합치와 닿지 않도록 제작하여 교합 시 결손부로 장치가 침하되지 않도록 해야 한다.

본 증례의 환자는 경구개에 국한된 static defect를 가 지고 있었으며 치조제가 ovoid한 형태여서 tapered한 형 태인 것에 비해 지지를 담당할 구개부 면적이 넓어 유리한 조건을 가지고 있었다. 또한 외과적 절제를 시행한 쪽의 구개 후방에 상악 결절이 남아 있어 전상악골과 양측 상 악 결절의 3지점에서 양호한 지지 기능을 얻을 수 있었다. 
폐쇄장치의 유지는 결손부의 외형에 맞추어 의치상을 연장시키고 탈착을 방해하지 않는 선에서 가능한 만큼의 언더컷을 이용해 얻어내야 한다. 이를 위해 본 증례의 환 자는 외과적 수술 시 부분층 피부이식을 시행해 결손부 변연을 이용할 수 있도록 하였다. 또한 최종 폐쇄장치 제 작 시 결손부의 후방과 측방 변연을 지나 연장되는 의치 상 부위를 정밀하게 제작하기 위해 변연 형성 과정에 주 의를 기울였으며 최종인상 채득 시 사용했던 인상재보다 더 낮은 점조도의 실리콘 인상재로 추가적인 wash impression을 시행하였다. 본 증례의 상악골 결손부는 연구 개로 연장되어 있지 않았고 양측의 상악 결절이 잔존하 였기 때문에 통상적인 폐쇄장치 제작 시 필요한 목운동 이나 침 삼킴과 같은 기능 운동은 시행하지 않았다. 같은 이유로 후방 한계 또한 일반적인 총의치에 준하여 양측 의 익돌상악절흔에서 이은 진동선 영역으로 설정하였다.

본 증례의 환자는 개구 장애 없이 정상적인 개구량을 보여 통상적인 방법으로 수직교합고경을 결정하였다. 하 지만 외과적 절제 시 저작 근육에 상흔이나 부종이 발생 하였거나 접형골 혹은 주변 근육 조직이 함께 절제되어 개구 장애가 발생한 경우에는 보다 수직교합고경을 낮 게 설정하여 상하악 전치부 치아 사이로 음식 덩어리를 넣을 수 있게 해야 한다. ${ }^{2}$

본 증례는 폐쇄장치를 장착한 후 1 년의 경과 관찰 동안 적절한 유지와 안정을 보였고 환자 또한 만족하였지만 향 후에도 지속적인 관찰을 통해 교합 관계 및 적합도를 확 인하고 필요에 따라 첨상하는 과정이 필요할 것이다.

\section{결론}

구강암 환자의 상악골 절제술이 계획되고 술후 보철 적 재건을 고려할 때에는 술전에 치과에 내원하는 과정 이 꼭 필요하다. 이를 통해 사전에 환자의 정보를 수집하 고 치료 계획을 수립하여 보다 체계적인 재건 술식을 도 모할 수 있다. 또한 이 모든 과정을 술전에 환자와 충분 히 상의하여 환자의 협조도를 높여야 한다.

Static border의 결손부를 가지며 양측 상악 결절과 전 상악골로부터 3점 지지를 확보할 수 있는 경우 술전 보철 계획 단계에서부터 수술후 폐쇄 단계, 이행 폐쇄 단계를 체계적으로 거쳐 최종 폐쇄장치를 제작함으로써 양호한 예후의 보철적 재건이 가능하다.

\section{ORCID}

Yoo-Jin Chung https://orcid.org/0000-0001-8679-7097

Joo-Hee Lee https://orcid.org/0000-0002-7907-3098

\section{References}

1. Oh WS, Roumanas E, Beumer J 3rd. Maxillofacial restoration after head and neck tumor therapy. Compend Contin Educ Dent 2007;28:70-6.

2. Beumer J 3rd, Marunick MT, Esposito SJ. Maxillofacial rehabilitation: prosthodontic and surgical management of cancer-related, acquired, and congenital defects of the head and neck. 3rd ed. Chicago; Quintessence Pub; 2011. p. 155-212.

3. Lang BR, Bruce RA. Presurgical maxillectomy prosthesis. J Prosthet Dent 1967;17:613-9. 


\section{상악골 부분 절제술을 받은 무치악 환자에서의 구강폐쇄장치 수복}

\section{정유진 ${ }^{1}$, 김종진 ${ }^{1}$, 백 진 $^{1}$, 차현석 $^{2}$, 이주희 ${ }^{2 *}$}

${ }^{1}$ 서울아산병원 치과보철과

${ }^{2}$ 울산대학교 의과대학 서울아산병원 치과보철학교실

상악골 결손을 갖고 있는 무치악 환자를 폐쇄장치로 수복할 때 임상가들은 많은 어려움을 겪게 된다. 결손부를 통한 공 기의 누출, 안정성과 지지의 부족, 감소된 의치 피개 면적은 의치의 흡착과 변연 폐쇄를 어렵게 한다. 본 증례는 편평상피 암에 이환된 우측 상악동 부위에 상악골 절제술을 받은 무치악 환자로 술전 치과 검진, 수술용 폐쇄장치, 이행 폐쇄장치, 그리고 최종 폐쇄장치에 이르는 단계적 치료 과정을 통해 보철적 재건을 완료하였다. 본 증례의 환자는 전상악골 및 양 측 상악 결절이 온전하며 한정된 크기의 결손부를 가져 적절한 유지와 지지를 갖는 폐쇄장치를 제작할 수 있었으며 심미 및 기능면에서 양호한 예후를 보였기에 이를 보고하는 바이다.

(구강회복응용과학지 2018;34(4):331-7)

주요어: 구강암; 상악골 절제술; 폐쇄장치; 완전 무치악 